Abstract

\title{
Metabolomic Analysis of Viscum album L Homeopathic Tinctures and Antitumor Studies in 3D Spheroid Models
}

\author{
Michelle Nonato de Oliveira Meloㄹ, Adriana Passos Oliveira1, Marcia Alves Marques Capella1, \\ Rafael Garrett ${ }^{2}$, Mirio Grazi ${ }^{3}$, Hartmut Ramm³, Tim Jaeger ${ }^{4}$, Stephan Baumgartner ${ }^{3,4}$, Carla \\ Holandino $^{1^{*}}$
}

1 - Multidisciplinar Laboratory of Pharmaceutical Sciences, Pharmacy College, Federal University of Rio de Janeiro, Rio de Janeiro - RJ, Brazil.

2- Metabolomic Laboratory (LabMeta/LADETEC), Chemistry College, Federal University of Rio de Janeiro, Rio de Janeiro - RJ, Brazil.

3 - Society for Cancer Research, Hiscia Institute, Arlesheim, Switzerland.

4 - Institute of Integrative Medicine, University of Witten/Herdecke, Herdecke, Germany.

* cholandino@gmail.com - https://orcid.org/0000-0002-6441-7281

Background The antitumoral efficacy of aqueous Viscum album extracts is attributed to the presence of lectins and viscotoxins. However, previous studies demonstrated an antitumoral activity of European V. album ethanolic homeopathic tinctures (VAHT) prepared according to homeopathic methodology. Aims To investigate the seasonal influences (summer and winter) in the metabolomic profile of $V$. album ssp. homeopathic mother tinctures (VAHT) and to evaluate the antitumoral activity of some VAHT in 3D tumor spheroid models. Methodology The following VAHT were prepared by ethanolic maceration: V. album ssp. album growing on Malus domestica, Quercus sp. and Ulmus sp.; V. album ssp. austriacum from Pinus sylvestris; V. album ssp. abietis from Abies alba. Chemical analyses were performed using liquid chromatography coupled to high-resolution mass spectrometry. Data was submitted to multivariate statistical analysis using principal component analysis (PCA) and Partial Least Squares Discriminant Analysis (PLSDA) in Metaboanalyst platform. The antitumor potential of VAHT $(0.5 \% \mathrm{v} / \mathrm{v})$ was conducted in 3D tumor spheroid models (MDA-MB231 cell line) by MTT for 72 hours. Results and discussion The PCA analysis explained $40 \%$ of data variation and clustered VAHT samples into 3 groups, emphasizing the chemical similarity between the botanical subspecies of $V$. album. Some key compounds were mainly responsible for this separation: pinobankasin hexose-pentose ( $V$. album ssp. abietis); citric acid ( $V$. album ssp. austriacum); malic acid (V. album ssp. album). The chemical differences among summer and winter samples, detected by PLSDA, were related to the Viscum album host trees. A significant reduction of $50 \%$ and $41 \%(\mathrm{p}<0.05)$ was detected in tumor cell viability when VAHT from Abies alba and Quercus sp. were compared to ethanol control, respectively. Conclusion The present study shows, for the first time, an overview of metabolomic profile from different homeopathic mother tinctures of European Viscum album and their promising antitumor activity in $3 \mathrm{D}$ spheroid model.

Keywords: Viscum album, homeopathic tinctures, antitumoral, metabolomic, spheroid

(C) International Journal of High Dilution Research.

Not for commercial purposes.

OPEN O ACCESS

Cite as: Int J High Dilution Res. 2019; 18(2): 18-18

https://doi.org/10.51910/ijhdr.v18i02.996 